\title{
Telling tales on either side of the teacher: methods of researching professional and biographical transformations in the context of Education
}

Mike Hayler mh101@brighton.ac.uk

Nadia Edmond N.Edmond@brighton.ac.uk

\begin{abstract}
:
This paper discusses the approaches and research methods used in two projects which examine professional transformations on 'either side' of the school teacher. The authors consider how the projects drew upon the different yet potentially complimentary methodological approaches of discourse analysis and autoethnography in the examination of professional identity. Following a description of the projects and the chosen methods, which includes discussion of the respective traditions from which they stem, the approaches are compared and contrasted through analysis of their application with a focus upon their various advantages and limitations within these particular contexts. The authors discuss these examples in terms of the wider discussion of quality and rigour in qualitative research and as a contribution to the debates on the complementarity of different qualitative approaches.
\end{abstract}

Key words: autoethnography; discourse analysis; qualitative research methods.

\section{Introduction}

This paper discusses the application and interpretation of the methodological approaches taken within two separate research projects which focus upon the experiences of individuals undergoing professional transformations on 'either side' of the school class teacher in England: teaching assistants (TAs) working alongside, and studying to become, teachers, and teachers becoming teacher educators (TEs). The former (TAs) project employed methods of discourse analysis while the latter (TEs) developed from autoethnography. Both approaches revealed conceptions of teacher professionalism from differing perspectives through their focus upon the processes of professional transformation, which we address elsewhere (Edmond \& Hayler, forthcoming). In the current paper we describe the design and application of our methods and draw out and discuss the areas of methodological convergence and divergence as part of the wider discussion about quality and rigour in qualitative educational research.

In reviewing the perennial issue of the criteria by which qualitative research should be evaluated Hammersley (Hammersley, 2007) has identified some of the fundamental differences that generate the 'methodological pluralism' of qualitative research as it is today. These include differing conceptions of scientific method and rigour, the perceived conflict between constructionism and realism, and the relationship between research and 'various other kinds of practical activity, including politics' (ibid: 297). Given these incompatibilities, a single set of guidelines for qualitative enquiry would not seem possible. The position represented by Hammersley's argument is that while the differences in perspective must be recognised 'some means needs to be found to at least 
reduce them, so as to increase the level of agreement in educational researchers' judgements about what is and is not good quality work' (Hammersley, 2007:301; see also Feuer et al, 2002 and Hammersley, 2005).

While we may not agree with Hammersley's further conclusion that guidelines for qualitative research are necessarily desirable we do agree that dialogue across different approaches, is an essential element in developing some level of consensus about quality within social and educational research. The current paper presents such a dialogue between our approaches while joining and contributing towards the wider discussion about the purpose and quality of educational research (see for example Hodkinson, 2004; Hammersley, 2005; Menter et al, 2010 and Murray, 2011). Elsewhere, Hammersley (2005a) examines the relationship between ethnography and discourse analysis, describing the wide range of research approaches that come under each of these headings while investigating similarities and tensions between them. Our dialogue here centres upon examples and comparisons of two particular approaches which can be seen as coming under those headings as our projects are both, to differing extent, examples of the overlap between various forms of ethnography and the analysis of discourse. Our common focus on the construction of meaning from 'memory' combined with the examination of interview data indicates that our approaches are both guided by, if not firmly embedded within, ethnography and discourse analysis as influenced primarily by post-structuralism. Tombouka and Ball (2003) emphasise the 'convergence' of these approaches while recognising the discontinuity and potential conflict in such a post-structuralist perspective, confirming the point that the potential of ethnography and discourse analysis to be combined depends largely upon how they are defined. As Hammersley (2005a:8) makes clear: 'Whether we find an unacceptable conflict here will depend upon what aspects of previously influential theoretical and methodological ideas we build into our definitions of ethnography, and also on how much emphasis we give to the need for internally consistent orientation.'

In common we have argued that our own studies and the different research methods that we have used contribute towards the examination and theorising of the complex processes of learning, while providing perspectives on the role that auto/biographical research and discourse analysis can play in that examination. In this sense the research projects meet the traditional research imperative of the production of knowledge, since they provide empirical data; namely the articulated experience of participants from which conclusions are drawn following analysis. However, as we discuss, these projects drew upon theoretical and methodological positions termed by, for example, Hammersley (2007) as 'constructionism' and 'activism' as our methods of research had in common the aim of examining the formation of professional identity and professional culture in the different areas of study and work on 'either side' of the classroom school teacher, through narrative stories of personal transformation. We encouraged and followed the participants in shaping their own selfnarratives and the ways in which they saw themselves and their professional place and role in different learning contexts. The processes by which we construct memory and the ways in which it informs learning and professional practice are central themes here: as Kierkegaard (1938) famously argued, while we can only live our lives forwards, we can really only understand them backwards. In terms of discourse analysis we remember and make sense of our history through interpretative repertoires, ideological dilemmas and subject positions (Edley, 2001:197).

In engagement with the issues of rigour and quality within educational research and as examples of developing forms and combinations of ethnography and discourse analysis in action, our discussion now brings the projects together side by side to consider them closely in terms of research design and methods employed. 


\section{Critical Discursive Psychology}

The first example considered in this paper is the analysis of interview data generated in the context of researching the process of professional transformation for teaching assistants who become teachers. This study arose within the education policy context in England which has resulted in an increasingly pedagogical role for teaching assistants (TAs), including taking responsibility for whole class teaching and meeting 'professional standards.' This policy approach has created learning and accreditation opportunities for a traditionally poorly-qualified workforce and specifically opened up work-based routes towards Qualified Teacher Status (QTS) for those working as teaching assistants.

The research, which was conducted between 2005 and 2008, aimed to examine notions of professionalism in education and to illuminate the role of Higher Education (HE) and individual agency within the processes of professional transformation.

Discourse analysis can be seen as an umbrella term comprising a range of different approaches categorised by Hammersley (2005) in terms of; those which are inspired primarily by poststructuralism, especially the work of Foucault, linguistics-based discourse analysis including those committed to locating patterns of discourse with a wider social context such as the critical discourse analysis of Fairclough (Fairclough, 1995), and the social psychological and sociological approaches of Potter and Whetherell (e.g. Potter and Whetherell, 1987). There is some debate over the extent to which these are distinct categories - as Hammersley concedes, both Fairclough's critical discourse analysis and Wetherell's critical discursive psychology (Whetherell, 1998) are influenced by poststructuralist ideas and while for him 'there still remains significant differences between these two projects' (Hammersley, 2005:4) Whetherell, Taylor and Yates (2001:10) emphasise the way different approaches to the analysis of discourse are "implicated in one another and shade together".

Our own approach is to celebrate the complimentary hues within the palette of Discourse Analysis while recognising the permeable borders that can be drawn between these various approaches. Elements of distinction and points of departure can certainly be found between and within them but our interest is in their methodological complimentarity.

The research of TAs primary interest was the construction of a graduate Teaching Assistant identity and how this is brought into being through discourse i.e. graduate and professional as components of identity are something that TAs 'do' (through discourse) rather than something that TAs 'are'. The research was concerned with how TAs present themselves with recourse to particular discursive constructions. What does TAs' talk reveal about how they construct work and study as contexts for activity and identity (including the power dynamics within these) and the 'learning affordances' (Billett, 2001) which these offer? What does it mean to become a graduate student teaching assistant and what kinds of actions and experiences are compatible with such positioning? In addressing these questions, the research can be seen as an example of Critical Discursive Psychology.

Within Discourse Analysis, Discursive Psychology sees language not as a resource (providing clues to what is going on in people's heads) but as itself the focus of study - examining the ways in which people talk about - or construct - things like attitudes memories or the process of learning. Talk is seen not just as communication but as social action, which is to say that all talk is also social practice and in talking we have specific 'action orientations' i.e. ends we are trying to achieve (for example, in asking you how you are I may not simply be communicating a request for information but also, and probably more importantly, establishing myself as a caring individual and our relationship as one in which it is appropriate for me to care and thereby implying that you should reciprocate). The business of Discursive Psychology is to examine the ways in which people use talk in social interactions and what that use of talk tells us about processes within the social construction of 
'reality'. Willig (2001:92) summarises Discursive Psychology as primarily concerned with how people use discursive resources in order to achieve interpersonal objectives in social interactions.

However, Critical Discursive Psychology insists upon seeing all sequences of talk as embedded within some kind of historical context and recognizes that when people talk they do so using a 'lexicon' or 'repertoire' of terms which has been provided for them by that history. Social groups with such a shared history are what Edley (Edley, 2001:190) calls a 'language culture'. This concept, closely related to that of 'community of practice' (Lave and Wenger, 1991) and 'Discourse' (Gee, 1992:107), provides members with a 'preferred' or hegemonic way of understanding and talking such that, from a range of possible ways of talking about the world, some will be encouraged and become the taken for granted 'true' view of the world.

This raises what Gee (2005) refers to as 'the frame problem' in recognising meaning as situated and opens a further area of potential debate around issues of validity and quality within educational research methodology. We return to these points in our conclusion but to summarise, our own position is that 'validity' in studies which seek to authentically represent lived experience depends upon confronting the inescapable problem of representation by recognising that the link between experience and representation are inevitably problematic (Denzin and Lincoln, 2005). Our work contributes to the 'rethinking of terms such as validity, generalizability and reliability' (ibid: 190) which Denzin and Lincoln called for in 2005. Similarly, the 'quality' of research can only be understood within the reader's framework of understanding which it may in itself change or extend. Issues of validity and quality within qualitative research are necessarily subjective, inter-subjective and determined by context.

Critical Discursive Psychology aims to capture the 'paradoxical relationship that exists between discourse and the speaking subject' (Edley, 2001:190). It aims to examine not only how identities are produced on and for particular occasions, but also how history or culture both impinge upon and are transformed by those performances. It draws attention to both the constructed and constructive capacities of discourse, showing how it comes to structure both subjective experience and our sense of who we are.

Three major analytical tools from discourse analysis and Discursive Psychology in particular were used; interpretative repertoires, ideological dilemmas and subject positions. The concept of interpretative repertoire derives from the work of Gilbert and Mulkay (1984) on accounts of scientific activity in which they found two quite separate ways of talking about scientific activity which they called 'interpretative repertoires'. Potter and Wetherell imported this concept into social psychology where they defined it as 'basically a lexicon or register of terms and metaphors drawn upon to characterize and evaluate actions and events' (Potter \& Wetherell, 1987:138).

Interpretative repertoires can be seen as 'plot lines' available to us to structure our narratives and are part and parcel of any community's 'common sense', providing a basis for shared social understanding. This research project used the transcripts of conversations with TAs to identify such interpretative repertoires in TAs' talk about their experience.

The second concept for organizing data within discourse analysis is that of 'ideological dilemmas'. This concept was introduced by Billig et al (1988) who problematized the prevailing (Marxist) notion that ideologies were integrated and coherent sets of ideas that served to represent the domination of the ruling sections of society as natural or inevitable. Billig and colleagues drew a distinction between 'intellectual ideologies' (those that conform to the classical Marxist definition) and 'lived ideologies'. These are composed of the beliefs, values and practices of a given society or culture and, rather than coherent and integrated, are inconsistent, fragmented and contradictory (Edley, 2001:203) and these contradictions emerge as 'dilemmas' in talk. 
The third concept of 'subject positions' originates in the work of Althusser (2001) on the 'Ideological State Apparatus', and refers to the way in which ideology creates or constructs subjects by drawing people into particular positions or identities. The way that people experience and feel about themselves and the world around them is, in part at least, a by-product of the way in which they interpret their positioning in terms of particular ideological or discursive regimes.

Using these analytical tools enabled a 'deconstruction' of TAs accounts revealing the way in which memories are told which legitimate and justify a 'professional' pedagogical identity as 'more than a $\mathrm{TA}^{\prime}$ ' thereby also revealing constructions of professionalism in education more generally.

This concern with how identities are constructed through memory was a feature of the second study discussed here which took an autoethnographic approach to researching the process of professional transformation from school-based teacher to university-based teacher educator.

\section{Analytic Autoethnography}

Emerging from the researcher's own experience, this enquiry took an autoethnographic approach by examining an individual self-narrative alongside those of six other teacher educators who work within university schools of education in England.

The research which was conducted in 2008, aimed to achieve an understanding of how the professional identity of teacher educators is both formed and represented by narratives of experience, raising issues about the ways in which people story and use memory, the role of others in the construction of identity through narrative and the nature of professionalism (Hayler, 2011).

Life history and biographical research has often focussed upon the development of professional identity which is widely regarded as a transformative and defining process of life experience (see for example Folkenflik, 1993; Erben, 1998 and West et al, 2007). The employment context of education and the biographical construction of teacher identities has been a central feature of this work (e.g. Bullough et al, 1992 and Goodson, 2003). Furlong and Smith (1996) and Furlong (2000) consider the pre-service preparation of teachers in the UK from the perspective of student teachers, while the distinctive contribution of higher education as a partner in this particular professional preparation is the focus of studies by Burn (2006) and Morrison and Pitfield (2006).

While a range of narrative, life-history and ethnographic research around memory and the lived experience of others continues to be the central focus for academic research (see for example Dawson, 2010, Thomson, 2011 and Goodson, 2012), and the examination of professional lives employs a variety of concepts regarding events and feelings (see short section on S-STEP below), autoethnography has increasingly become the term of choice for a range of methods of research, analysis and writing that employ the researcher's personal experience as a way of investigating and understanding the sub-cultures and the wider cultures of the societies within which we live and work. Hayano (1979), who coined the term 'autoethnography', used it to refer to the work of 'insider' anthropologists, researching their 'own people' (p101) arguing that in a post- colonial era ethnographers need to study their own social worlds and sub-cultures. We might imagine autoethnography as a particular collection of tools within the qualitative research workshop which focus upon the memories of events, feelings, thoughts and emotions which contribute through varying methods of recall, collection and analysis, towards different types of systematic introspection in order to illuminate and to facilitate understanding. It has evolved and widened to include a rubric of research approaches, methods and techniques such as 'narratives of the self' (Richardson, 1994), 'personal experience narratives' (Denzin, 1989), 'first person accounts'(Ellis, 1998), 'reflective ethnographies' (Ellis and Bochner 1996), 'evocative narratives' (Tillman-Healy 
1999), 'collaborative autobiography' (Goldman, 1993) and, as applied to teacher education by Clandinin and Connelly (1994), 'personal experience methods', to name only a few. Within all of these approaches the researcher is deeply self-identified through explicit and reflective selfobservation.

Debates continue around these methods and what that systematic introspection should entail. Discussion of the genre often refers to what Anderson (2006) critiques as 'evocative autoethnography' which draws upon postmodern sensibilities and rejects realist and analytic ethnographic traditions. Anderson proposes the term 'Analytic Autoethnography' as a way of reframing and reclaiming autoethnography within what he terms 'the analytic ethnographic paradigm.' The intention is to re-open and develop a research approach in which the researcher is deeply self-identified as a member of the researched group while maintaining the qualitative principles of traditional symbolic interactionism.

Drawing from both Polkinghorne's psychological research (1988) and from the philosophical ideas of Paul Ricoeur (1984) this research with teacher educators sits with the body of work developed by Clandinin and Connelly $(1991,1999)$, Connelly and Clandinnin $(1988,1990,2001)$ and with the Self Study of Teacher Education Practices (S-STEP) special interest group. The focus of this group's work has been largely upon the use of narrative to support the education and professional development of teachers and teacher educators through reflective self-study (Russell and Munby, 1992; Russell and Loughran, 2007). While this approach could be framed as 'activism' (Hammersley, 2007) since it aims to change practice, the notion of self-study for research purposes and self-study for professional development are not seen as in any way contradictory. Recent research using S-STEP methodology has included seeking to develop practice by placing teacher educators' own narratives at the centre of the process in order to examine the role of collaboration in self-study (Chryst et al, 2008; Crafton and Smolin, 2008) and exploring the tensions between teaching, methodology and theory in teacher education (Hamilton, 2008). Here the production of new knowledge and understanding are key criteria in the quality of research, alongside the development of practice as part, not just as a result, of the process of research.

The five features of analytic autoethnography: complete member research; analytical reflexivity; narrative visibility of the researcher's self; dialogue with informants beyond the self and a commitment to theoretical analysis, proposed by Anderson (2006:378) formed the criteria and a protocol for the research with teacher educators. The original self-narrative of learning, written by the researcher, became both data and research tool, forming the starting point for discussion of commonalities and differences of experience between the teacher educators. This conception of autobiographical writing as a collaboration that is 'waiting to happen' (Marcus, 1994) again links closely with Anderson's (2006) principal point of connecting self-narrative with the narrative of others in ethnographic study and emphasises the potential of the relationship between selfnarrative and life history interview methods where the self-narrative of the researcher is itself foregrounded.

\section{Exploring Teaching Assistants' constructions of 'professional'}

\section{identity}

Biographic narrative accounts were collected through interviews conducted with 19 TAs who were also students at various stages of study routes towards Qualified Teacher Status (QTS). The interviews took the form of extended (60-90 minute) conversations structured around: the TAs education and employment history; when and how the individual came to be a teaching assistant; 
when and how the TA came to be on the particular HE course of study; the TAs experiences while on the course; the TAs anticipated future. The interviews were tape recorded and transcribed and transcripts were sent to interviewees inviting any comments, clarification or elaboration.

The main 'discursive objects' (or topics) arising in TAs discursive constructions (or stories) were: educational experience and qualifications; motherhood, employment (and significantly the combination of the two); the role, status and pay of TAs in schools, the role (status and pay) of the individual TA; different 'types' of TAs ; consequences of pursing the course of HE study in terms of knowledge/expertise gained; 'graduate' status and changes in work role/identity.

From the perspective of critical discursive psychology, the analysis was premised on seeing this talk not as revealing of the 'historical facts' associated with TAs participation in the HE programme but rather as revealing of the way in which accounts of this personal history are marshalled in the construction of an identity. Consequently, the interview transcripts were analysed according to a questioning framework adapted from Willig (2001) and Hart (2007) and summarised in table 1 below:

- How are 'discursive objects' (the things which are being talked about) embedded within interpretative repertoires including wider discourses? How do TAs talk about becoming TAs and progressing into teaching? What recourse do they make to wider discourses such as notions of 'career' and 'motherhood' for example?

- What is the "action orientation" within the discourse? What 'work' is the interpretative repertoire doing in the exchange? What is it designed to communicate and how? The concern here was to identify the rhetorical strategies and devices that TAs' talk used such as, referential (how groups are referred to as 'in' or 'out') evaluative strategies (how judgements about these groups are communicated and justified), the use of "topoi"1 (van Dijk, 2000:215)

- How do TAs 'position' themselves in relation to others and their circumstances, within the discourse? This can be seen as the 'identity work' of the communication - how are TAs using talk to present a particular version/story of themselves?

- Are there any ideological dilemmas in the discourses; here the concern is to identify contradictions and/or inconsistencies in the discourse? What are the implications for practice presented? What are the possibilities for action mapped by the discursive constructions?

In the accounts of how individual TAs came to be on the course it is possible to see common story lines of opportunity for further study when younger thwarted by circumstances, and of talent spotted and opportunity seized later in life. This common 'plot line' can be seen as making recourse to broader gendered 'repertoires' in which opportunity thwarted is framed in terms of marriage and motherhood as when Julie says " at the time I was going to get married and have children and I found myself a job so that was it really". Similarly, divorce or separations are presented as opening up opportunities as when Julie says that after her divorce "it was suddenly (.) right you are not in my way anymore (.) I can do it. So that is why I then signed myself up on this course (.) to get a career again (.) a different career".

The 'action orientation' of the TAs talk can be understood in terms of legitimising claims to (semi) professional status in which different rhetorical strategies are used (which themselves can be seen

\footnotetext{
${ }^{1}$ Topoi, represent premises that are taken for granted, as self-evident and as sufficient reasons to accept the conclusion.
} 
as embedded in wider repertoires). A key discursive construction that emerged, for example, was that of "different types of TAs" in which TAs are constructed as either "career minded' or 'professional' in their approach or not. In contrast to those who see TA work as a kind of domestic service "they are just there to wash all the pots", are those who see it as a more demanding role "the TA is there to fill in the gaps for the teacher (.) it's not a little job you go and do and potter about at (.) and you do whatever they throw at you" which presents opportunities for progression. Within this construction, TAs can position themselves as 'more like a teacher' in that they share 'professionalism' expressed in terms of responsibility (inability to leave the job behind), commitment to professional development (in which HE plays an important role), expertise which informs judgement and critique of practice and engagement in professional discourse as well as 'doing what teachers do'. Using 'professionalism' as a construct with these characteristics, TAs position themselves in an intermediate 'professional' position and HE as having a privileged role in legitimating this intermediate status particularly through sanctioning participation in teachers' practice and giving access to knowledge which can be shared with colleagues in school and/or used to articulate commentary on and critique of practice.

The analysis also reveals 'ideological dilemmas' emergent in TAs talk an example being in the way that TAs talk about the role of study and experience in their professionalism. Different and conflicting constructions emerge in TAs talk with descriptions of the transformation resulting from participation in $\mathrm{HE}$ alongside a reluctance to claim to know more than fellow TAs who have not benefited from study. These ideological dilemmas indicate that taking on a professional identity depends on subtle and complex inter-relationships between academic learning and expertise, practice and relationships in which $\mathrm{HE}$ and experience are presented as playing crucial but distinct and sometimes contradictory roles.

The critical discursive psychology approach applied to this data provides an understanding of 'professionalism' in education through an analysis of the way in which the (semi) professional identity of TAs progressing into teaching is discursively constructed and legitimated.

Professionalism in education is an equally prominent and no-less variedly defined theme within the self-narratives of the teacher educators.

\section{Exploring Teacher Educators' self-narratives}

The project with teacher educators began with the researcher writing a self-narrative of personal memories of learning and the experiences of becoming and being a teacher and then a teacher educator. The story was shared with six other teacher educators who recorded interview/discussions about their own experiences as learners, teachers and teacher educators. They then wrote versions of their own stories. While the initial story formed a central part of the investigation, the engagement with the voices of others became the key vehicle of questioning and developing that understanding and the way in which to share and compare accounts of experiences so as to extend that understanding further.

The interview discussions with the teacher educators were purposefully led by the researcher's own educational narrative writing which had been written with the planned intention of sharing it with 6 other teacher educators. Here the writing itself became a method of inquiry. While the story as written became the first piece of data and then part of the research method through sharing it with others, writing it was firstly what Richardson (2000) terms as 'Creative Analytic Practice' where process and product are displayed as deeply intertwined. Auto/biographical writing is an invitation for the reader to examine their own memories after reading the memories of another, for while the 
process of writing a self-narrative invokes memory and brings new understanding within a current context for the writer, it also opens this possibility for the reader.

Influenced by the life-story and popular memory interview approaches (Popular Memory Group, 1982) the researcher drew upon elements from a combination of these for the largely unstructured interviews by encouraging four key interactions during discussions with the participants: between interviewer and interviewee, which was initially facilitated by sharing the story and by sharing professional experiences in teacher education; between individual experience and public policy, encouraged by discussion of memories relating directly to policies such as the eleven plus exam, the national numeracy strategy or structural changes within teacher education and the how these had affected the participants ; between the present and the past through discussion of experiences as learners and as teachers; and between memory and identity through shared reflections upon how the TEs saw themselves as influenced and altered by memories of formative experience (Thomson, 1994). Following the interviews each of the participants wrote their own self-narratives which they sent to the researcher.

A narrative analysis developed from Sartre's (1963) progressive/regressive method was employed as a way of considering and representing the 12 sets of data: the researcher's own story, 6 interview transcripts and 5 pieces of writing from the other participants.

While not known as an ethnographer Sartre (1963:85-166) constructs a method that emphasises memories and the consequences of particular decisions and actions by looking first forward to the conclusion of a set of acts and then working back through the 'subjects' interpretations of the conditions and situations that shaped the decisions and actions in question. In his famous biography of Flaubert, for example, Sartre (1993) uses this method to demonstrate how individuals internalise and express social events and values by illuminating those structures, firstly from the lived perspective of Flaubert (from his private and published writing) and then by investigating and describing the relevant social structures such as class, family and era themselves.

This forwards and backwards movement in time, characteristic of so much oral history and life history interviews and writing (e.g. Thompson, 1978; Goodson, 1992; Thomson, 1994) locates the participants and their actions ('subjects' and their 'projects' in Sartre's terms) within culture as a set of 'interpretive practices.' This is clearly not an approach that attempts to capture the totality of an individual or a group's way of life. The focus here is upon:

... interpreted slices, glimpses and specimens of interaction that display how cultural practices, connected to structural formations and narrative texts, are experienced at a particular time and place by interacting individuals (Denzin, 1997:247).

Using this approach, the analysis of TEs data first looked forward from particular memories and accounts in the data towards a perceived conclusion or consequence of those experiences, decisions and actions, and then looked back towards the historical, cultural and biographical conditions that moved the narrator. The data was then organised into a set of collective narratives under three themes relating to 'being a TE', 'being a teacher' and 'being a learner.' The uniqueness of participants' experience is illuminated in the episodes revealed alongside similarities and commonalities with others. For example, Michael's memories of being threatened with the 'special school' by his head teacher when he was ten, Jan's recall of her feelings of disillusionment as a teacher of English or Brian's recollection of his Father's pride in him as a learner, all illuminate social structures and behaviours through individual perspectives. While the parallel review and discussion situates and connects those experiences within the wider context of the relevant structures such as family and the education system, the fact that the participants chose to tell these stories in the way they do is equally telling. The presentation and discussion of data begins as it were, in the future by 
considering the experiences of being a teacher educator through the themes or 'sites'. Subsequent sections move backwards in time through participant perspectives on being teachers and being learners. While the researcher's own story presents a more chronologically conventional narrative it too follows this forwards and backwards perspective through narration.

This offers a picture of teacher education 'culture in practice' (Fiske, 1994:195) by placing sets of experiences and perspectives alongside each other in much the same way as the study of TAs worked with the data gathered through interview. It was possible to look forward to the conclusion of a number of experiences and acts remembered and recorded in the data such as, for example, the Jan's story of her decision to move into teacher education which she describes as leading to her developing new understandings of higher education and the distinct role of the teacher educator. Jan presents this as leading in turn to what she presents as a successful and largely happy career in teacher education. Reading regressively back from that same decision of Jan's towards the historical, cultural and biographical circumstances that informed those experiences and actions allows for a consideration of the wider context and dynamic of the time. Jan tells a story of her feelings about literacy and literature which came into conflict with the national literacy strategy she was required to teach in school, causing her to feel disillusioned and contributing towards the decision to move on. Jan's narrative on the origins and development of her feelings and beliefs about stories, literacy and teaching take on a new significance in this context. Experiences are placed in time and space illuminating the unique features of our lives while revealing commonalities that we share with each other. Sartre argued that each of us is a universal singular, 'universalising in our singularity the crises and experiences of our epoch' (Sartre, 1981: ix).

This particular analytical approach allows for a reconsideration of the wider societal events of the earlier time and how these may have also influenced what seem at first like individual decisions and actions.

An important element of the progressive/regressive approach is the foregrounding of agency in the existential 'manipulation' of memory. Sartre rejected psychological determinism where the events of our lives largely determine our psychological development and dictate our behaviour, in favour of a process which develops from unconscious to increasingly conscious choice-making in the way we engage with and make meaning from memory, offering degrees of agency not only in what we do now and in the future but how we construct and use past experience. The particular and significant role of higher education as provider of education, employment and narrative context in the development of agency emerges most clearly across these stories of experience.

The notion of 'agency' is also foregrounded in Critical Discursive Psychology which conceptualizes the speaker as an active agent who uses discursive strategies to manage stake in social interactions but sees these 'discursive strategies' as embedded within socio-historical 'discursive practices' which enable and legitimate particular ways of being.

\section{Conclusion}

Having shared the aims, some elements of the derivation, and the particular application of our respective methods, we now discuss some points of convergence and divergence within these examples of using discourse analysis and ethnography while considering some of the key themes within the wider discussion of quality in qualitative research.

While working on this paper we often found ourselves saying 'that's just like ...' as we considered the concepts, assumptions and nomenclature of each other's work. We came to see common features of our respective approaches as the result of a kind of 'convergent evolution' in particular 
versions of Ethnography and Discourse Analysis. In spite of their differing origins, independent sources and largely separate development there is in practice and on the surface at least, many parallels in critical discursive psychology and autoethnography.

In discussing the question of whether ethnography and discourse analysis are incompatible or complementary, Hammersley (2005) concedes that each is an umbrella term for a range of heterogeneous approaches deriving and evolving from particular methodological and epistemological positions. Madill, Jordan and Shirley (2000) propose three distinct epistemological frameworks: realism, contextual constructionism and radical constructionism and we can see ethnography originating in a realist epistemology and discourse analysis in radical constructionism.

The autoethnographic memory work of Hayler and the critical discursive psychology of Edmond provide examples of the way in which specific approaches within these two traditions have converged and/or are compatible.

Both approaches take an emic perspective in which the emphasis is on allowing critical categories and meanings to emerge from the research encounter rather than imposing these from existing models.

Both approaches locate the individual and their actions within their socio-historical context: we can see how for example Sartre's insight of universal singularity relates to notions of discourse and communities of practice. In this respect, both approaches are 'critical realist' in that they are premised on the assumption that "the way we perceive fact, particularly in the social realm, depends partly upon our beliefs and expectations' (Bunge, 1993) and that discursive accounts are grounded in social practices whose underlying logic and structure can, in principle, be discovered .

Both reject the extreme of radical relativism and posit the existence of social structures independent of human understanding. Both emphasise the constitutive role of discourse and 'meaning making' as reflecting the availability of particular discourses to make sense of experience. As a result both approaches understand psychological phenomena such as memory, attribution and identity as discursive actions rather than as cognitive processes. Memories are something that people do rather than something people have.

These shared assumptions underpin the approaches used and highlight the potential complementarity of these methods exemplified in our previous article where we were able to bring them together in a meaningful way (Edmond and Hayler, 2013).

However, while we can make the case for the convergent evolution of these approaches resulting in shared fundamental principles and complementarity, the similarities in research practice in data collection and analysis resulting from this 'convergence' must not obscure the significance of the different starting points and histories of the evolution of these research methods. They may look similar but they are different species in many ways.

These differences are most visible when we consider the role of the researcher and the process of analysis.

While the first piece of data collection for Edmond was to interview the TAs, for Hayler it was the writing of a self-narrative which was later shared with the TEs. As discussed, writing the subjective story is itself regarded as both analytic and creative in autoethnographic research, whereas the patterns, meanings and discursive objects of others are the analytical focus of critical discursive psychology. Sharing the self-narrative prior to interview influenced the shape of the following discussions with the TEs' and the self-narrative was itself part of the data. This approach would not 
be used as a method within critical discursive psychology where, while data may be collected from talk generated by consideration of a narrative, the narrative itself would not form part of that data. The relationship between our own stories and the stories of others is a central concern of critical discursive enquiry but the researcher is not often self-identified or visible within the text.

The different approaches (and their respective 'communities') have also given rise to particular solutions to the problem of 'quality' within qualitative research. With doctoral destinations and criteria in mind we both needed to shape and frame our methods of analysis to fit the purpose. In terms of the particular qualitative approaches taken we needed to articulate what constituted quality and rigour in our analyses in ways that legitimated our respective claims to join particular "research cultures" ((Hodkinson, 2004).

Edmond (2008) developed a questioning framework for analysis from Willig (2001) and Hart (2007) and worked to avoid Antaki et al's 'analytic shortcomings' in relation to discourse analysis (Antaki, Billig, Edwards ad Potter, 2003) with particular attention to the dangers of circularity in identifying discourses and circularity in identifying mental constructs. Antaki et al argue that, in identifying and naming 'repertoires' or discourses, the analyst needs to do more than merely use the term to summarise talk. The 'circularity' derives from the fact that quotes, which provide the justification for claiming the existence of a particular discourse, are then explained in terms of this entity. The analysis needs to extend beyond identification to an explication of the use of the particular discourse in the interaction or a description of how wider patterns of talk and mobilised by the speaker in the particular context.

The parallel danger is that of circularity in identifying mental constructs. Traditional social psychology has sought to explain external actions (including discursive actions) in terms of inner mental processes such as 'memory' and 'beliefs'. The discursive psychologist resists positing mental entities and concentrates on examining the use of psychological constructs in discourse. Rather than claiming that phrases used by respondents such as 'I think' or 'I believe' give direct access to the person's inner thoughts or feelings and citing these inner thoughts or feelings as the reason for the utterance, Edmond (2008) focussed on how this language enables the respondent to achieve their ends through talk.

Hayler adopted Anderson's (2006) proposals for analytic autoethnography as a way of developing and framing methodology in relation to more traditional ethnographic qualitative research. Although this sometimes felt like an uneasy compromise it allowed the development of a version of analytic autoethnography that follows Anderson's five principles without surrendering a deepening commitment to an interpretive, narrative perspective: (1) the researcher was a complete member researcher within teacher education; (2) the researcher followed and demonstrated the selfconscious introspection of analytic reflexivity through writing; (3) the researcher is a highly visible social actor within the text as his own feelings and experiences are incorporated into the story and form a key part of the data and the method; (4) the process of sharing stories and interviews with the other participants ensured a dialogue with informants beyond the self; and (5) the research demonstrates a commitment to theoretical analysis in using the progressive/regressive method of interpretation and presentation through narrative analysis.

The autoethnographic expedition for understanding how narratives of experience form and represent professional identity did not naturally lead to new, sturdy definitions and methods for establishing absolute truth. It did lead to a deeper understanding of teacher education and autoethnography which contributes towards new professional knowledge in a number of ways. While this meets the broad research imperative of illuminating new ways of knowing and understanding, we might also see this as a form of 'activism' in that it offers ideas and new perspectives on practice which are shared beyond the researcher. At its best autoethnography 
provides both descriptive and theoretical insight combining the analytic with the evocative. The methods used illuminate the often hidden and private experiences that give meaning to everyday life, making things more visible without making them simple. The reader, the audience, makes meaning from the way the story is told. The stories themselves have an evocative validity as they bring the news of experience and response from one person's world to another.

The shared critical realist position of our studies meant that bringing them together enabled a kind of methodological triangulation. We both sought for our analysis to identify themes and categories emerging from the data. We had not described derived categories in the same way but as Madill et al (2000) argue, reliability is properly assessed qualitatively in terms of "consistency of meaning" (ibid: 6-7) and this consistency of meaning was apparent.

One of the striking things about the dialogue we have engaged in while preparing this paper is that, as well as becoming more familiar with each other's approaches we have come to understand our own in a new way. Hearing the other narrative and shaping our own in response has changed the way we see things in much the same way as our participants developed their own understanding of themselves within the process of research.

In setting out to examine the construction of professional identities, these projects were both concerned with the value of articulated experience as a key source for exploring the relationship between the individual and the cultures and subcultures within which they are situated. We chose to start in different places and took a different approach to analysis. There was clearly a good deal of happenstance in the development of our methodologies as we came across research tools and methods of analysis which suited the purpose for our respective research journeys.

We both found that using these methods of research was rewarding, exciting and liberating, but never settling or reassuring. In common these approaches offer opportunities to examine and analyse the connections between self-narrative and social structures in distinctively grounded ways. While the data and discussions with TAs and TEs illuminate several of the key issues about professional transformation in the first decades of the $21^{\text {st }}$ Century it is clearly not the purpose of these methods to identify universal processes or generalisations. If this is to be a central criterion of quality in qualitative enquiry then our methods do not fit the bill. The stories are inevitably incomplete, fragmented and partial because all stories are. The analysis is incomplete and partial as all analysis is. Furthermore we would argue that this is true of all methods in qualitative research but that where there is convergence on ontological and epistemological positions, a kind of methodological triangulation becomes possible which enriches and broadens the analysis.

\section{References}

Althusser, L. (2001). Lenin and Philosophy and Other Essays (B. Brewster, Trans.). New York: Monthly Review Press.

Anderson, L. (2006). Analytic autoethnography. Journal of Contemporary Ethnography, 35, 373-395.

Antaki, C., Billig, M.G., Edwards, D. and Potter, J.A., (2003). Discourse analysis means doing analysis: a Critique of six analytic shortcomings. Discourse Analysis Online, 1 Available from: http://www.shu.ac.uk/daol/articles/v1/n1/a1/antaki2002002-paper.html

Billett, S. (2001). Co-participation: Affordance and Engagement at work. New Directions for Adult and Continuing Education, 92, 63-72. 
Billig, M., Condor, S., Edwards, D., Gane, M., Middleton, D. J., \& Radley, A. R. (1988). Ideological Dilemmas: A social psychology of everyday thinking. London: Sage.

Bullough, R.V., Knowles, J.G. and Crow, N.A. (1992). Emerging as a New Teacher. New York: Routledge.

Bunge, M. (1993). Realism and antirealism in social science. Theory and Decision, 35, 207-235.

Burn, K. (2006). Promoting critical conversations: the distinctive contribution of higher education as a partner in the professional preparation of new teachers. Journal of Education for Teaching, $32(3), 243-259$.

Chryst, C., Lassonde, C. \& Mckay, Z. (2008). The invisible researcher: new insights into the role of collaboration in self-study. In: Heston, M. L., Tidwell, D. L., East, K. K. \& Fitzgerald, L. M. (Eds.) The Seventh International Conference on Self-Study of Teacher Education Practices. Pathways to Change in Teacher Education: Dialogue, Diversity and Self-Study (50-53). Herstmonceux Castle, East Sussex, England: S-Step/University of Northern lowa.

Clandinin, D. J. and Connelly, F. M. (1991). Narrative and story in practice and research. In: Schon, D. A. (Ed.) The Reflective Turn: Case studies in and on educational practice (258-283). New York: Teachers College Press.

Clandinin, D. J. and Connelly, F. M. (1994). Personal experience methods. In: Denzin, N. K. \& Lincoln, Y. S. (Eds.) Handbook of Qualitative Research (413-427). Thousand Oaks, CA: Sage.

Clandinin, D. J. and Connelly, F. M. (1999). Narrative inquiry. In Keeves, J. P. and Lakomski, G. (Eds.) Issues in Educational Research (132-140), Kidlington. Oxford: Pergamon.

Connelly, F. M. \& Clandinin, D. J. (1988). Teachers as Curriculum Planners. Toronto, ON: OISE Press.

Connelly, F. M. and Clandinin, D. J. (1990). Stories of experience and narrative inquiry. Educational Researcher, 19 (5), 2-14.

Connelly, F. M. and Clandinin, D. J. (2001). Exploring the landscape of Canadian teacher education. Asia Pacific Journal of Teacher Education and Development, 4 (1), 1-11.

Crafton, L. \& Smolin, L. (2008). The language of collaboration: moving beyond self and other. In: Heston, M. L., Tidwell, D. L., East, K. K. \& Fitzgerald, L. M. (Eds.) The Seventh International Conference on Self-Study of Teacher Education Practices. Pathways to Change in Teacher Education: Dialogue, Diversity and Self-Study (82-86). Herstmonceux Castle, East Sussex, England: S-Step/University of Northern lowa.

Dawson, G. (2007). Making Peace with the Past: memories, trauma and the Irish trouble. Manchester: Manchester University Press.

Denzin, N.K. and Lincoln, Y.S. (2005). The Sage Handbook of Qualitative Research. Thousand Oaks, CA: Sage.

Denzin, N. K. (1989). Interpretive Biography. Newbury Park, CA: Sage.

Denzin, N. K. (1997). Interpretive Ethnography: Ethnographic Practices for the 21st Century. Thousand Oaks, CA: Sage. 
Edley, N. (2001). Analysing Masculinity: Interpretative Repertoires, Ideological Dilemmas and Subject Positions. In: Discourse as Data: A Guide for Analysis (189-228). London: Sage in Association with OUP.

Edmond, N. and Hayler, M. (2013). On either side of the teacher: perspectives on professionalism in education. Journal of Education for Teaching, 39:2 (forthcoming).

Edmond, N. (2008). The Role of Higher Education in Work-based Learning for Primary Teaching Assistants. Unpublished Ed.D thesis, University of Brighton, Brighton.

Ellis, C. (1998). Exploring loss through autoethnographic inquiry: Autoethnographic stories, coconstructed narratives, and interactive interviews. In: Harvey, J. H. (Ed.) Perspectives on Loss: A sourcebook, (49-60). Philadelphia: Taylor and Francis.

Ellis, C. \& Bochner, A. P. (Eds.) (1996). Composing Ethnography: Alternative forms of qualitative writing. Walnut Creek, CA: Alta-Mira.

Erben, M. (Ed.) (1998). Biography and Education: A Reader. London: Falmer.

Fairclough, N. (1995). Critical Discourse Analysis. London: Longman.

Feuer, M. J., Towne, L. and Shavelson, R. J. (2002). Scientific culture and educational research. Educational Researcher, 31(8), 4-14.

Fiske, J. (1994). Audiencing: Cultural practice and cultural studies. In: Denzin, N. K. \& Lincoln, Y. S. (Eds.) The Handbook of Qualitative Research (189-198). Thousand Oaks, CA: Sage.

Folkenflik, R. (Ed.) (1993). The Culture of Autobiography: Constructions of Self-Representation. Stanford, CA: Stanford University Press.

Furlong, J. (2000). Higher Education and the New Professionalism for Teachers: realising the potential of partnership - a discussion paper. London, CVCP: SCOP.

Furlong, J. \& Smith., R. (Eds.) (1996). The Role of Higher Education in Initial Teacher Training, London: Kogan Page.

Gee, J. P. (1992). The Social Mind: Language, Ideology and Social Practice. New York: Bergin and Garvey.

Gee, J.P. (1999/2005). An introduction to discourse analysis: theory and method (second edition). London: Routledge.

Gilbert, N., \& Mulkay, M. (1984). Opening Pandoras Box: a Sociological Analysis of Scientists Discourse. Cambridge: Cambridge University Press.

Goldman, A. (1993). Is that what she said? The politics of collaborative autobiography. Cultural Critique. 25, 177-204.

Goodson, I. F. (Ed.) (1992). Studying Teachers Lives. London: Routledge.

Goodson, I. F. (2003). Professional Knowledge, Professional Lives: Studies in Education and Change. Maidenhead: Open University Press.

Goodson, I. (2012). Developing Narrative Theory: life history and personal representation. Abingdon/New York: Routledge. 
Hamilton, M. L. (2008). Studying My Practice: Exploring tensions in my teaching, my methodology and my theory. In: Heston, M. L., Tidwell, D. L., East, K. K. \& Fitzgerald, L. M. (Eds.) The Seventh International Conference on Self-Study of Teacher Education Practices. Pathways to Change in Teacher Education: Dialogue, Diversity and Self-Study, (163-167). Herstmonceux Castle, East Sussex, England: S-Step/University of Northern lowa.

Hammersley, M. (2005). Ethnography and discourse analysis: incompatible or complementary? Polifonia (10), 1-20.

Hammersley, M. (2005a). Methodological disagreement and the problem of quality. ESRC TLRP seminar series: Quality in Educational Research, 1-10.

Hammersley, M. (2007). The issue of quality in qualitative research. International Journal of Research \& Method in Education, 30(3), 287-305.

Hart, C. (2007). Critical discourse analysis and conceptualisation: Mental spaces, blended spaces and discourse spaces in the British National Party. In: C. Hart \& D. Lukes (Eds.). Cognitive Linguistics in Critical Discourse Analysis: Application and Theory (107-131). Newcastle: Cambridge Scholars Press.

Hayano, D. (1979) Auto-ethnography: Paradigms, problems, and prospects. Human Organization, 38, 113-120.

Hayler, M. (2009). The Self-Narrative Character of Teacher Educators Pedagogy. Unpublished EdD thesis, University of Brighton.

Hayler, M. (2011). Autoethnography, Self-Narrative and Teacher Education. Rotterdam: Sense.

Hodkinson, P. (2004). Research as a form of work: expertise, community and methodological objectivite. British Education Research Journal, 30(1), 9-26.

Kierkegaard, S. (1938) The Journals of Soren Kierkegaard. Oxford: Oxford University Press.

Lave, J. and Wenger, E. (1991) Situated Learning: Legitimate Peripheral Participation. Cambridge: Cambridge University Press

Madill, A., Jordan, A., \& Shirley, C. (2000). Objectivity and reliability in qualitative analysis: realist, contextualist and radical constructionist epistemologies. British Journal of Psychology, 91(1), $1-20$.

Marcus, L. (1994). Autobiographical Discourses. Manchester: Manchester University Press.

Menter, I., Hulme, M., Murray, J., Campbell, A., Hextall, I., Jones, M., Mahony, P., Proctor, R. and Wall, K. (2010). Teacher education research in the UK: the state of the art. Revue Suisse des sciences de leducation, 32(1), 121-142.

Morrison, L. \& Pitfield, M. (2006). Flexibility in initial teacher education: implications for pedagogy and practice. Journal of Education for Teaching, 32 (2), 185-196.

Murray, J. (2011). Teacher education research in England: present realities, future possibilities. Research Intelligence, 116, 14-16. 
Teacher Education Research in England: present realities, future possibilities? Research Intelligence, $116,14-16$.

Polkinghorne, D. (1988). Narrative Knowing and Human Science. New York: State University of New York Press.

Popular Memory Group (1982). Popular Memory: theory, politics, method. In: Johnson, R. \& McLennan, G. (Eds.) Making Histories: Studies in History, Writing and Politics. London: Hutchinson.

Potter, J., \& Wetherell, M. (1987). Discourse and Social Psychology: Beyond Attitudes and Behaviour. London: Sage.

Richardson, L. (1994). Writing: a method of inquiry. In: Denzin, N. K. \& Lincoln, Y. S. (Eds.) The Handbook of Qualitative Research, (516-529). Thousand Oaks, CA: Sage.

Richardson, L. (2000). Writing: A method of Inquiry. In: Denzin, N. K. \& Lincoln, Y. S. (Eds.) Handbook of Qualitative Research, (923-948). London: Sage.

Ricoeur, P. (1984). Time and Narrative (1). Chicago: University of Chicago Press.

Russell, T. and Loughran, J. (Eds.). (2007) Enacting a Pedagogy of Teacher Education. London: Routledge.

Russell, T. and Munby, H. (Eds.) (1992). Teachers and teaching: from classroom to reflection. London: Falmer Press.

Sartre, J-P. (1963). The Problem of Method. London, Methuen.

Sartre, J-P. (1981) The Family Idiot: Gustave Flaubert, 1821-1857, Vol 1. Chicago: Chicago University Press.

Sartre, J-P. (1993). The Family Idiot: Gustave Flaubert 1821/1857 Vol 5. Chicago: University of Chicago Press.

Tamboukou, M. \& Ball, S. J. (Eds.) (2003). Dangerous encounters: genealogy and ethnography. New York: Peter Lang.

Thompson, P. (1978). The Voice of the Past: Oral History. Oxford: Oxford University Press.

Thomson, A. (1994). Anzac Memories: living with the legend. Oxford: Oxford University Press.

Thomson, A. (2011). Moving Stories: an intimate history of four women across two continent.

Manchester: Manchester University Press

Tillmann-Healy, L. (1999). Life projects: A narrative ethnography of a gay-straight friendship.

Unpublished doctoral dissertation: University of South Florida.

van Dijk, T. A. (2000). The reality of racism. On analyzing parliamentary debates on immigration. In:

G. Zurstiege (Ed.), Festschrift für die Wirklichkeit (211-226). Wiesbaden: Westdeutscher Verlag.

Wetherell, M. (1998). Positioning and Interpretative Repertoires: Conversation Analysis and PostStructuralism in Dialogue. Discourse and Society, (9), 387-412. 
Telling tales on either side of the teacher 18

Wetherell, M., Taylor, S., \& Yates, S. J. (2001). Discourse as Data: A guide for analysis. London: Open University in association with Sage.

West, L., Alheit, P., Anderson, A, S. and Merrill, B. (2007). Using Biographical and Life History Approaches in the Study of Adult and Life-Long learning: European Perspectives. Frankfurt: Peter Lang.

Willig, C. (2001). Introducing Qualitative Research in Psychology: Adventures in Theory and Method. Buckingham: Open University Press. 